\title{
Giant Left Coronary Artery Aneurysm in a Patient with Mixed Connective Tissue Disease
}

\author{
Kazuo Asada, Masaru Hatano, Norihiko Takeda, Yasutomi Higashikuni, Kan Saito, \\ Nobukazu Ishizaka, Yasunobu Hirata and Ryozo Nagai
}

Key words: coronary aneurysm, mixed connective tissue disease, collagen disease

(DOI: 10.2169/internalmedicine.46.0283)
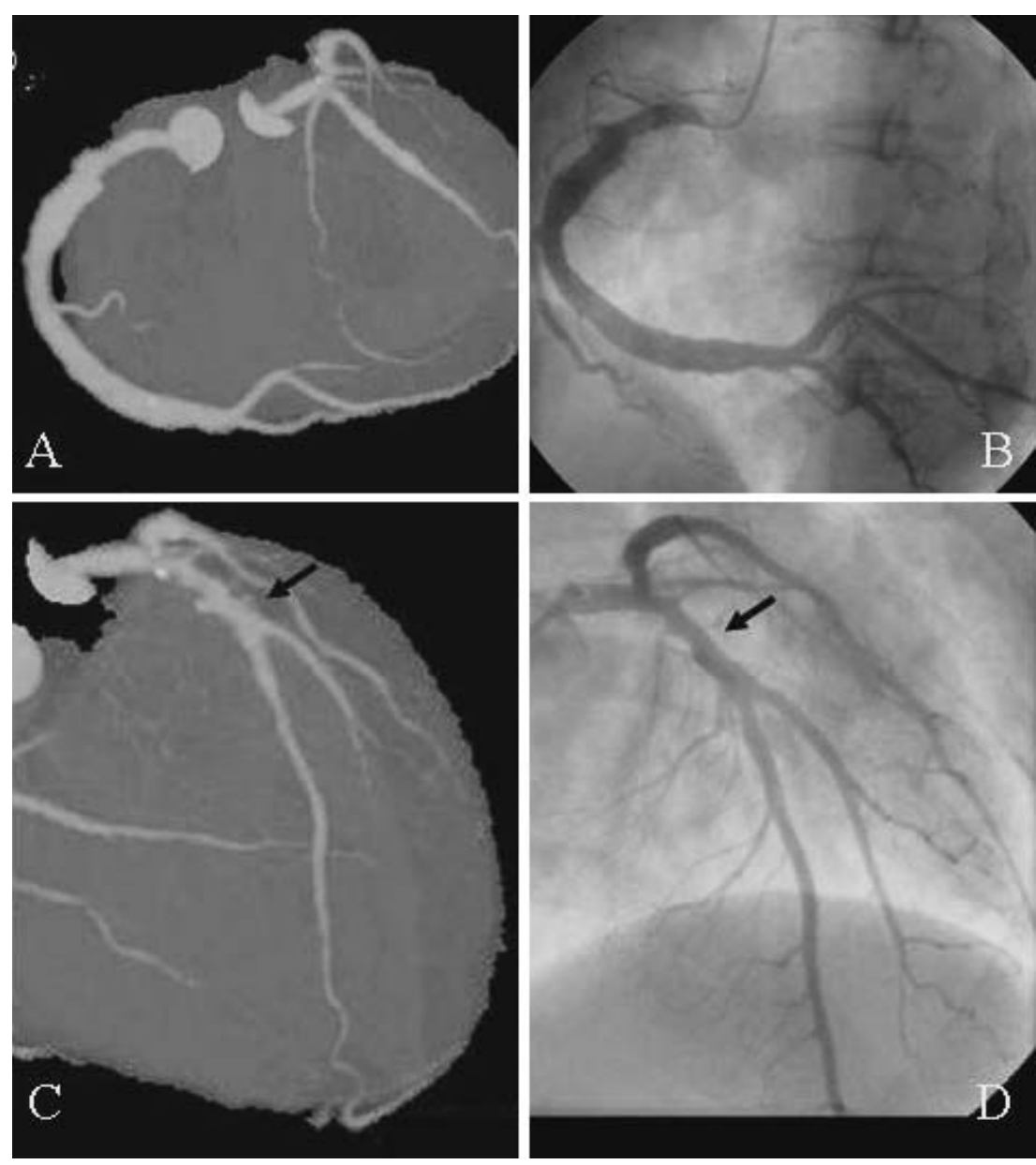

Picture 1. Coronary CT angiography (A, C) and coronary angiography (B, D) revealed mild dilatation of the right coronary artery $(\mathrm{A}, \mathrm{B})$, and an irregular lesion in the left anterior descending artery $(C, D$, arrow).

A 49-year-old woman with a diagnosis of mixed connective tissue disease was referred to our hospital complaining of exertional dyspnea. To rule out the existence of coronary artery disease, we performed coronary angiography (CAG), and it showed an irregular coronary lesion with $<50 \%$ luminal diameter obstruction of the left anterior descending coro- 


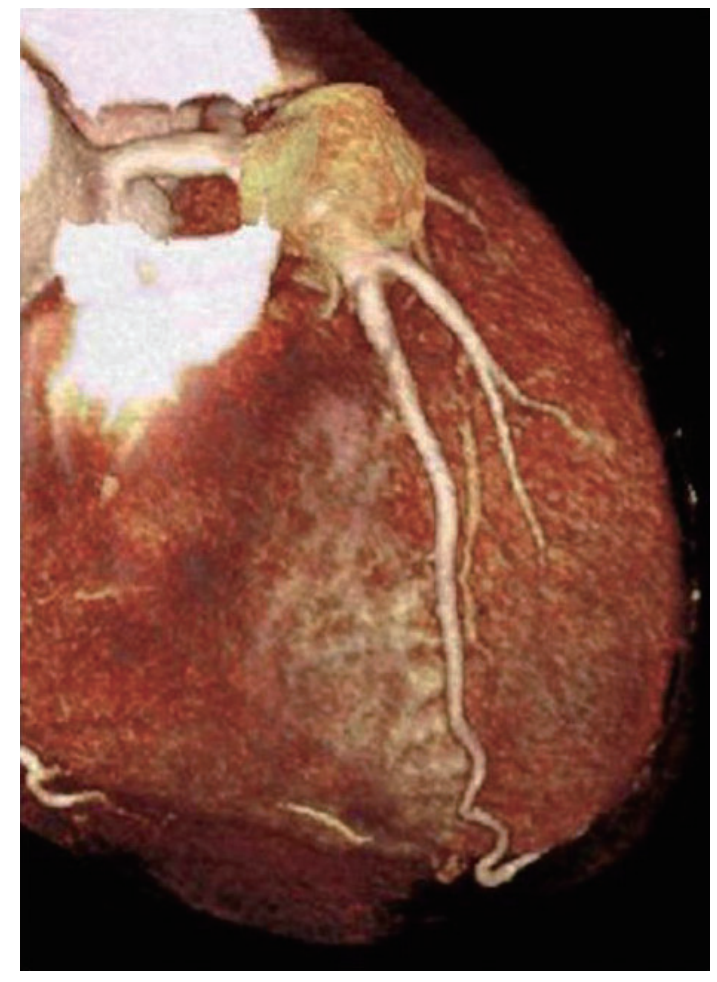

Picture 2. Coronary CT angiography, demonstrating a giant coronary artery aneurysm with a ball thrombus of the left anterior descending artery. nary artery (LAD) and mild dilatation of the right coronary artery (Picture 1B, 1D). Coronary CT angiography demonstrated almost identical changes as in CAG (Picture $1 \mathrm{~A}, 1 \mathrm{C})$. In addition, it revealed a giant coronary artery aneurysm with a ball thrombus in the LAD, which was not noted on CAG (Picture 2).

Coronary aneurysm is not unusual in patients with collagen disorders (1). Coronary CT angiography seems to be beneficial in these patients, since the modality is useful not only in analyzing the coronary artery, but also in detecting a coronary aneurysm even if it is thrombosed.

\section{References}

1. Daoud AS, Pankin D, Tulgan H, Florentin RA. Aneurysms of the coronary artery. Report of ten cases and review of literature. Am J
Cardiol 11: 228-237, 1963.

\footnotetext{
(C) 2007 The Japanese Society of Internal Medicine http://www.naika.or.jp/imindex.html
} 